\title{
Neutral polysaccharide from Panax notoginseng enhanced cyclophosphamide antitumor efficacy in hepatoma $\mathrm{H} 22-$ bearing mice
}

Yan-Hong Liu ${ }^{1+}$, Hua-Yan Qin ${ }^{1,2+}$, Yuan-Yuan Zhong ${ }^{1 \dagger}$, Shuang Li ${ }^{1}$, Hua-Jing Wang ${ }^{1}$, Hong Wang ${ }^{3}$, Li-Ling Chen ${ }^{4}$, Xiang Tang ${ }^{1}$, Ya-Lin Li ${ }^{1}$, Zhong-Yi Qian ${ }^{5}$, Huai-Yu Li' ${ }^{6}$, Lei Zhang ${ }^{7}$ and Tong Chen ${ }^{1 *}$

\begin{abstract}
Background: Our previous studies demonstrated that the administration of crude Polysaccharide from Panax notoginseng (CPPN) can effectively prolong the lifespan of tumor-bearing mice via boosting the host immune system as well as weak cytotoxicity against hepatocellular carcinoma (HCC). In the present study, Neutral Polysaccharide (NPPN) were further purified from crude polysaccharide isolated from panax notoginseng. The effects of NPPN on the immune function and hematopoietic function of mice with low immunity and myelosuppression induced by cyclophosphamide (CTX) were investigated. The effect of NPPN combined with CTX on the tumor inhibition rate of the $\mathrm{H} 22$ tumor-bearing mice and the impact of NPPN on the proliferation of $\mathrm{H} 22$ liver cancer cells in vitro were investigated.
\end{abstract}

Methods: CPPN was obtained by water extraction and alcohol precipitation method, and further purified by DEAE Sepharose Fast Flow ion exchange resin column. NPPN was added to the immunosuppressed with myelosuppression mice induced by CTX. Thymus index, spleen index, lymphocyte proliferation stimulation index by adding of concanavalin A, determination of serum hemolysin, NK cell activity assay, mice carbon clearance experiment, blood count tests were detected. The tumor inhibition rate of the $\mathrm{H} 22$ tumor-bearing mice treated with NPPN combined with CTX was recorded.

Results: NPPN and 4 kinds of acid polysaccharide from Panax notoginseng (APPN) were successfully isolated from the CPPN by DEAE Sepharose Fast Flow ion exchange resin column. NPPN inhibited the growth of H22 cells and significantly increase the tumor inhibition rate of the $\mathrm{H} 22$ tumor-bearing mice combined with CTX. The elevation of the cellular and humoral immunity levels as well as a variety of blood count tests indicators of immunosuppressive with myelosuppression mice may contribute to the antitumor activity of NPPN.

(Continued on next page)

\footnotetext{
*Correspondence: chentongdoc@163.com

†Yan-Hong Liu, Hua-Yan Qin and Yuan-Yuan Zhong contributed equally to this work.

'School of Pharmaceutical Sciences and Yunnan Key Laboratory of

Pharmacology for Natural Products, Kunming Medical University, Kunming 650500, China

Full list of author information is available at the end of the article
}

C C The Author(s). 2021 Open Access This article is licensed under a Creative Commons Attribution 4.0 International License, which permits use, sharing, adaptation, distribution and reproduction in any medium or format, as long as you give appropriate credit to the original author(s) and the source, provide a link to the Creative Commons licence, and indicate if changes were made. The images or other third party material in this article are included in the article's Creative Commons licence, unless indicated otherwise in a credit line to the material. If material is not included in the article's Creative Commons licence and your intended use is not permitted by statutory regulation or exceeds the permitted use, you will need to obtain permission directly from the copyright holder. To view a copy of this licence, visit http://creativecommons.org/licenses/by/4.0/. The Creative Commons Public Domain Dedication waiver (http://creativecommons.org/publicdomain/zero/1.0/) applies to the data made available in this article, unless otherwise stated in a credit line to the data. 
(Continued from previous page)

Conclusion: NPPN has a potential antitumor activity for the treatment of liver cancer combined with cyclophosphamide.

Keywords: Panax notoginseng, Neutral polysaccharide from Panax notoginseng, Purification, Myelosuppression, Immunosuppression, Combined medication, Liver cancer

\section{Background}

Primary liver cancer is one of the most common cancer in the world. Approximately 70 to $85 \%$ of primary liver cancer cases are hepatocellular carcinoma (HCC), which is the third leading cause of cancer-related death following gastric cancer and lung cancer, and causes approximately one million deaths every year worldwide [1]. The early stage of HCC usually shows no or only mild symptoms. HCC usually is diagnosed at the late stage when the chance of the curative treatments such as resection, transplantation, or local ablation has gone. As a result, the median survival following diagnosis is only approximately $6-20$ months $[1,2]$. The late stage HCC is commonly treated by systemic anticancer therapies such as chemotherapy with unsatisfied efficacy. In addition, chemotherapy such as Cyclophosphamide (CTX) massively depletes bone marrow progenitor cells resulting in anemia, neutropenia, and thrombocytopenia. Patients may suffer from complications such as fatigue, dizziness, bruising, hemorrhage, and potentially fatal opportunistic infections. To reduce these side effects, drug dosage and frequency may have to be limited. In turn, the treatment efficacy may be compromised [3-5] CTX is one of the most widely used antitumor agents in clinical chemotherapy for the treatment of a broad spectrum of human cancers including lymphomas, some forms of brain cancer, leukemia as well as some solid tumors. It belongs to the nitrogen mustard group which can induce DNA damages in the fast dividing tumor cells by nonspecifically alkylating the DNA of tumor cells. When the DNA damages are severe enough then tumor cells are forced to undergo apoptosis modulated by $\mathrm{p} 53$, a protein maintaining the genome integrity. Thus, tumor growth could be suppressed. However, serious side effects such as myelosuppression, one of the most important blood toxicities, are often caused by the application of CTX [6]. The post-chemotherapy leucopenia is the most common phenomenon and may easily result in a concurrent lethal infection. Currently, the most common treatments for chemotherapy-induced myelosuppression are blood transfusion, growth factor injections, or bone marrow transplantation for an inevitable complete myeloablation. Such managements are costly and limited effectiveness [7]. New approaches are urgently needed to ameliorate the immune system for the prevention of chemotherapy-induced bone marrow suppression and improvement of cancer patient survival and quality of life. It has been demonstrated that Polysaccharides from various sources enhanced antitumor therapy via boosting the immune system of cancer patients with relatively nontoxic [8-11]. Polysaccharide from Panax notoginseng (PPN) has been shown to stimulate murine spleen lymphocyte proliferation in vivo and in vitro. It also abolished the suppression of the $\mathrm{T}$ cell by cyclosporin A [11]. The $1500 \mathrm{k}$ Da fraction of the extraction from roots of Panax notoginseng activated the reticuloendothelial system [12]. IFN- $\gamma$ and IFN- $\alpha$ in mouse spleen lymphocytes and peritoneal macrophage cell culture have been eleven by the application of the water soluble, high molecular weight fraction of an extraction of Panax notoginseng [8]. In our previous studies, we successfully developed a reliable and effective method to extract alcohol insoluble CPPN from the industrial notoginsenosides extract residues with the contents of polysaccharides as 56\% [13]. The administration of CPPN alone can effectively prolong the lifespan of tumor-bearing mice via boosting the host immune system as well as weak cytotoxicity against HCC [14].

In the present study, to validate the polysaccharides of CPPN playing a major role in immuno-stimulation, NPPN fraction has been further purified from CPPN to increase the content of polysaccharides from 56 to $88.4 \%$. To evaluate the effects of NPPN on the immune function and hematopoietic function of Kunming mice, NPPN has been combined with CTX and applied to H22 tumor-bearing mice. Though CTX slowed down tumor growth, it resulted in sever immunosuppressive and myelosuppression in mice. The application of NPPN improved hematopoietic status while combined with CTX, consequentially, enhanced the antitumor efficacy of CTX.

\section{Methods \\ Experimental animals}

Female Kunming mice (18-22 g) were provided by the Laboratory Animal Center of Kunming Medical University. Animals were housed in an SPF environment. Environment conditions were a temperature of $20 \pm 4{ }^{\circ} \mathrm{C}$, the humidity of $50 \pm 10 \%$, the lighting of $350 \mathrm{~lx}$, and a 12/12 light/dark cycle. During housing, animals were given a normal diet. All animals were monitored twice daily for health status, no 
abnormal reaction appeared in the all group. All groups of mice were put to death by cervical dislocation after inhalation of ether and coma. All experimental procedures were performed in accordance with the Guidelines of Animal Experiments from the Committee of Medical Ethics, National Health Department of China and approved by the Ethics Committee of Kunming Medical University. All sections of this report adhere to the ARRIVE Guidelines for reporting animal research. A completed ARRIVE Guidelines checklist is included in checklist S1.

\section{Extraction of CPPN}

The extraction of CPPN from the root of Panax notoginseng has been described previously [14]. Briefly, $100 \mathrm{~g}$ dried Panax notoginseng medicinal residue was mixed with $1000 \mathrm{~g}$ distilled water in a $2000 \mathrm{~mL}$ beaker. The beaker was then kept in a boiling water bath for $6 \mathrm{~h}$ then taken out and cooled down to room temperature. The liquid was poured out as the first extraction. Then, $800 \mathrm{~g}$ distilled water was added to the remaining solid portion and the beaker was kept in a boiling water bath again for an additional $6 \mathrm{~h}$. Then the liquid was collected as the second extraction. Followed, $600 \mathrm{~g}$ distilled water was added to the remaining solid portion. The beaker was kept in a boiling water bath again for an additional $6 \mathrm{~h}$. Then, the liquid portion was collected as the third extraction. All three extractions were combined then centrifuged at $8000 \mathrm{rpm}$ for $10 \mathrm{~min}$. The supernatant was collected and condensed to $1 / 10$ of the original volume in a vacuum condenser at $80^{\circ} \mathrm{C}$. Followed, three volumes of $100 \%$ ethanol were gradually added to the concentrated extraction with stirring. The mixture was then kept at $4{ }^{\circ} \mathrm{C}$ for $24 \mathrm{~h}$ followed by centrifugation at $8000 \mathrm{rpm}$ for $10 \mathrm{~min}$. After the removal of the supernatant, the CPPN was washed with $75 \%$ ethanol and dried in a drying oven at $50{ }^{\circ} \mathrm{C}$.

\section{Extract NPPN from CPPN}

NPPN was further extracted from CPPN by DEAE Sepharose Fast Flow anion exchange chromatography column (GE Healthcare, Little Chalfont, Buckinghamshire, UK) $(24 \times 400 \mathrm{~mm})$ according to manufactory instructions. CPPN was dissolved in distilled water at a concentration of $30 \mathrm{mg} \cdot \mathrm{mL}^{-1}$. The solution was centrifuged at 8000 $\mathrm{rpm}$ for $10 \mathrm{~min}$. The supernatant was then filtered through a $0.45 \mu \mathrm{m}$ microporous membrane and $25 \mathrm{~mL}$ solution was loaded to the column. The first elution used distilled water and collected by $5 \mathrm{~mL}$ eluate per tube was collected. Until the anthrone-sulfuric acid reagent was added to the last tube and heat in a water bath for $15 \mathrm{~min}$ and cool in an ice bath for $15 \mathrm{~min}$ and no coloration was observed. Replace the eluent and elute sequentially with $0.1,0.2,0.3$, and $0.4 \mathrm{~mol} \cdot \mathrm{L}^{-1}$ sodium chloride solution, and the eluent was collected, $5 \mathrm{~mL}$ per tube, and collected until the anthrone-sulfuric acid reagent was added and heat in a water bath for $15 \mathrm{~min}$ and cool in an ice bath for $15 \mathrm{~min}$ and no coloration was observed. Determination of the polysaccharide content of Panax notoginseng by the method of anthrone-sulfuric acid [15]. The number of eluted tubes was plotted on the abscissa and the absorbance was plotted on the ordinate. The eluent was combined according to the elution curve. And then the eluent was concentrated under reduced pressure by rotary evaporator at $80^{\circ} \mathrm{C}$ to about $50 \mathrm{~mL}$. Transfer $50 \mathrm{~mL}$ of rotary evaporation liquid to a dialysis bag (Biosharp, Jiangsu, China).having a molecular weight of $14,000 \mathrm{Da}$ by a pipette. The dialysis bag was sealed and placed in $2000 \mathrm{~mL}$ of distilled water for dialysis for $36 \mathrm{~h}$ and changed every $9 \mathrm{~h}$.

\section{Determination of molecular weight by high performance gel permeation chromatography}

The weight average molecular weight $(\mathrm{Mw})$, number average molecular weight $(\mathrm{Mn})$, and dispersity were measured by high performance gel permeation Chromatography (HPGPC). Chromatographic conditions: Agilent 1260 HPLC system (Agilent Technologies, Santa Clara, CA, USA); data processing system: Agilent GPC software. Mobile phase: $0.1 \mathrm{~mol} \cdot \mathrm{L}^{-1} \mathrm{NaCl}$; column: Shodex Ohpak SB-804HQ gel column (Shodex, Japan); flow rate: $0.5 \mathrm{~mL} \cdot \mathrm{min}^{-1}$; Column temperature: $35^{\circ} \mathrm{C}$; detector: differential detector; injection volume: $20 \mu \mathrm{L}$. A standard curve was established using Dextran $\mathrm{T}$ series standards (National Institutes for Food and Drug Control, Beijing, China) (standard molecular weights of 4600, 7100, 10, 000, 21,400, 41,100, 84,400, 133,800 Da, respectively). The above-mentioned one part of NPPN and the four parts of APPN were dissolved into an aqueous solution having a concentration of about $10 \mathrm{mg} \cdot \mathrm{mL}^{-1}$, and filtered through a $0.22 \mu \mathrm{m}$ microporous membrane, and then injected.

\section{Determination of the content of PPN by an anthrone- sulfuric acid method}

Determination of the polysaccharide content of Panax notoginseng by the method of anthrone-sulfuric acid [15]. Preparation of an anthrone-sulfuric acid reagent: Take about $0.1 \mathrm{~g}$ of anthrone, accurately weighed, add $80 \%$ sulfuric acid solution to dissolve, transfer to a 100 $\mathrm{mL}$ volumetric flask, and place it in a dark place. Preparation of standards solution and drawing of its absorbance value and concentration standard curve: Take about $10 \mathrm{mg}$ of D-anhydrous glucose reference substance (National Institutes for Food and Drug Control, Beijing, China) dried to constant weight at $105^{\circ} \mathrm{C}$, accurately weighed, placed in a $50 \mathrm{~mL}$ volumetric flask, plus dissolve the appropriate amount of distilled water, add distilled water to volume, and store at $4{ }^{\circ} \mathrm{C}$. Precisely 
measure $0.0,0.2,0.4,0.6,0.8,1.0 \mathrm{~mL}$ of the reference solution in a test tube, add distilled water to $2.0 \mathrm{~mL}$, accurately measure $5.0 \mathrm{~mL}$ of the anthrone sulfuric acid reagent into the test tube, shake well, and heat in a boiling water bath for 15 mins, quickly removed into the ice water bath for 15 mins. The absorbance value of the reference solution at $625 \mathrm{~nm}$ was determined. Taking the absorbance of the D-anhydrous glucose reference solution as the ordinate and the concentration of the Danhydrous glucose reference solution as the abscissa, a standard curve of the absorbance value and the concentration of the reference solution is plotted.

Determination of Polysaccharide content of Panax notoginseng: Take about $10 \mathrm{mg}$ of the test sample, accurately weigh it into a beaker, add distilled water, dissolve in a water bath, transfer to a $25 \mathrm{~mL}$ volumetric flask and add distilled water to volume. Accurately measure $0.4 \mathrm{~mL}$ in a test tube, measure the absorbance value according to the above method, and take the absorbance value into the above standard curve to calculate the concentration of the test sample, and calculate the content of the polysaccharide in the test sample.

\section{Establishment and grouping of cyclophosphamide- induced immunosuppression and myelosuppression mouse models}

SPF Kunming mice were randomly divided into 5 groups, 10 in each group, 5 groups were: low, medium, and high doses of NPPN groups (93 $\mathrm{mg} \cdot \mathrm{kg}^{-1}, \quad 188 \mathrm{mg} \cdot \mathrm{kg}^{-1}, \quad 375 \mathrm{mg} \cdot \mathrm{kg}^{-1}$ ), model group, and normal group. The low, medium, and high doses of NPPN groups were continuously intragastrically administered with different concentrations of NPPN solution for 10 days. The model group and the normal group were continuously administrated with normal saline for 10 days. On the 6th day of intragastric administration, except for the normal group, the other groups were intraperitoneally injected with CTX (Shengdi, Jiangsu, China) $\left(80 \mathrm{mg} \cdot \mathrm{kg}^{-1} \cdot \mathrm{d}\right)$ for 5 days, and the indexes were determined on the 11 th day.

\section{Determination of thymus and spleen index}

On the 11th day, mice in each group were killed after weighed. Then, the thymus and spleen were removed and weighed. The thymus index was calculated as thymus weight divided by body weight. Spleen index was calculated as spleen weight divided by body weight.

\section{Determination of lymphocyte proliferation stimulation index by adding of concanavalin a}

Preparation of mouse spleen lymphocytes [16]: The spleen of mice was isolated under aseptic conditions, placed in a dish containing an appropriate amount of sterile Hank's solution (Solarbio, Beijing, China), and the fat and connective tissue were removed, ground in a mortar, and filtered through a 200 mesh screen. The filtrate was centrifuged at $1000 \mathrm{r} \cdot \mathrm{min}^{-1}$ for $10 \mathrm{mins}$, the supernatant was discarded, 3 volumes of red blood cell lysate (Solarbio, Beijing, China) was added and the cells were lysed for 10 mins on ice. After centrifugation at $4{ }^{\circ} \mathrm{C}$, the supernatant was discarded, Hank's solution washed the cells twice, and the supernatant was discarded after centrifugation at $4{ }^{\circ} \mathrm{C}$. Resuspend in $1.5 \mathrm{~mL}$ of complete medium, count live cells, and adjust the number of cells to $2 \times 10^{6}$ cells $/ \mathrm{mL}$. The mouse spleen cell suspension $\left(2 \times 10^{6}\right.$ cells $\left./ \mathrm{mL}\right)$ was inoculated into a 96-well culture plate at $200 \mu \mathrm{L} /$ well. Each sample was provided with a stimulation well and control well, and three parallel holes were set for each. The stimulation well was added with Concanavalin A (Solarbio, Beijing, China) containing $0.1 \mathrm{mg} \cdot \mathrm{mL}^{-1} 15 \mu \mathrm{L}$ of the culture solution. The cells were placed in a $37^{\circ} \mathrm{C} 5 \% \mathrm{CO}_{2}$ incubator for $44 \mathrm{~h}$, and then $20 \mu \mathrm{L}\left(5 \mathrm{mg} \cdot \mathrm{mL}^{-1}\right)$ of the MTT solution (Solarbio, Beijing, China), was added to continue the culture for $4 \mathrm{~h}, 100 \mu \mathrm{L}$ of the supernatant was discarded, $150 \mu \mathrm{L}$ of the triplet solution was added to each well, and the mixture was shaken and dissolved for 10 mins. The optical density (OD) value at the wavelength of $570 \mathrm{~nm}$ was measured by a microplate reader.

The stimulation index (SI) was calculated: $\mathrm{SI}=$ stimulation hole OD value / control hole OD value.

\section{Determination of serum hemolysin}

Sheep red blood cells (SRBC) (Solarbio, Beijing, China) were prepared into $2 \%(\mathrm{v} / \mathrm{v})$ cell suspensions with normal saline, and on the 7 th day of intragastric administration, all groups were intraperitoneally injected with 0.2 $\mathrm{mL}$ for sensitization. After immunization for 4 days, blood was taken from the iliac vein in the orbit and centrifuged in a centrifuge tube. After centrifugation at $4000 \mathrm{r} \cdot \mathrm{min}^{-1}$ for $10 \mathrm{mins}$, the serum was separated and collected, and the serum was diluted 100-fold with physiological saline. The diluted serum $1 \mathrm{~mL}, 10 \%$ SRBC $0.5 \mathrm{~mL}$, and $1 \mathrm{~mL} \mathrm{10 \%} \mathrm{complement} \mathrm{(Solarbio,} \mathrm{Beijing,}$ China) were sequentially added to the test tube. The same volume of physiological saline was used as a blank control, shaken and placed in a $37^{\circ} \mathrm{C}$ water bath for 30 min, transferred to an ice bath to terminate the reaction, centrifuged at $2000 \mathrm{r} \cdot \mathrm{min}^{-1}$ for $10 \mathrm{mins}$, the supernatant was taken, each set with 3 parallel wells, the OD value was measured using a microplate reader $(540 \mathrm{~nm})$ [17].

The phagocytic index a assay using carbon clearance test On the 11th day, mice in each group were killed after weighed and the phagocytic index $\alpha$ and the phagocytic rate $\mathrm{k}$ of each group have been determined. After the last administration, each group of mice was injected with 
a dose of $0.1 \mathrm{~mL} / 10 \mathrm{~g}$ of Indian ink diluted 4 times with physiological saline through the tail vein, and immediately after the injection, $20 \mu \mathrm{L}$ of blood was taken at 2 and 10 mins after the ink was injected, and added to 2 $\mathrm{mL}$ of $0.1 \% \mathrm{Na}_{2} \mathrm{CO}_{3}$ solution, shake well, and use $\mathrm{Na}_{2} \mathrm{CO}_{3}$ solution as blank control to measure the OD at $600 \mathrm{~nm}$, and set up 3 parallel holes. The mice were sacrificed and the liver and spleen were taken and weighed. The phagocytic index $\alpha$ [18] is calculated as follows. $\alpha=$ $\kappa^{1 / 3} \times$ body weight / (liver weight + spleen weight) where $\kappa=\left(\operatorname{lgOD} \mathrm{D}_{1}-\lg \mathrm{OD}_{2}\right) /\left(\mathrm{T}_{2}-\mathrm{T}_{1}\right)$.

\section{NK cell activity assay}

Target cells (Yac-1 cells, Shanghai Institutes for Biological Sciences, Shanghai, China): Target cells were subcultured $24 \mathrm{~h}$ before the experiment. The cells were washed three times with Hank's solution and adjusted to a cell concentration of $4 \times 10^{5}$ cells $/ \mathrm{mL}$ with RPMI 1640 complete medium (Thermo Fisher Scientific, Waltham, MA, USA) for use.

Preparation of spleen cell suspension (effector cells): The spleen of the mice was isolated under aseptic conditions, placed in a dish containing an appropriate amount of sterile Hank's solution, and the fat and connective tissue were removed, ground in a mortar, filtered through a 200 mesh screen, and the filtrate was collected and centrifuged at $1000 \mathrm{r} / \mathrm{min}$ for $10 \mathrm{mins}$, the supernatant was discarded. Add 3 times volume of red blood cell lysate, lyse on ice for 10 mins, centrifuge at $4{ }^{\circ} \mathrm{C}$, discard the supernatant, wash the cells twice with Hank's solution, resuspend with $0.5 \mathrm{~mL}$ of complete medium, count live cells, adjust the number of cells to $2 \times 10^{7}$ cells $/ \mathrm{mL}$. Add $100 \mu \mathrm{L}$ each of effector cell fluid and target cell fluid to a 96-well plate, and set the target cell natural release well $(100 \mu \mathrm{L}$ target cell $+100 \mu \mathrm{L}$ complete medium $)$ and the maximum release well $(100 \mu \mathrm{L}$ target cell + $100 \mu \mathrm{L}$ of $1 \%$ NP-40 solution (Solarbio, Beijing, China), each set of 3 parallel wells, incubated for $48 \mathrm{~h}$ in a $37^{\circ} \mathrm{C}$, $5 \% \mathrm{CO}_{2}$ incubator.

The supernatant of each well was aspirated and the lactate dehydrogenase (LDH) activity was determined by the LDH kit (Jiancheng, Nanjing, China) and determined OD value at $450 \mathrm{~nm}$.

NK cell activity $(\%)=($ measured well OD - natural release pore OD) / (maximum release pore OD - natural release pore OD) $\times 100 \%$.

\section{Blood count tests}

Before the animal was sacrificed, blood was taken from the iliac vein in the eyelid. EDTA- $K_{2}$ was added to the test tube as an anticoagulant reagent, and the blood count tests were measured by an automatic blood cell analyzer (Sysmex, Japan).
Effect of NPPN combined with CTX on tumor inhibition rate in the $\mathrm{H} 22$ tumor-bearing mice Grouping and administration of mice Kunming SPF mice were randomly divided into 9 groups, 10 in each group, followed by (1) control group, (2) saline group, (3) CTX group (25 $\left.\mathrm{mg} \cdot \mathrm{kg}^{-1}\right)$, (4) Low dose NPPN group (93 mg. $\mathrm{kg}^{-1}$ ), (5) medium dose NPPN group (188 $\left.\mathrm{mg} \cdot \mathrm{kg}^{-1}\right)$, (6) high dose NPPN group (375 mg. $\left.\mathrm{kg}^{-1}\right)$, (7) NPPN low dose $\left(93 \mathrm{mg} \cdot \mathrm{kg}^{-1}\right.$ ) + CTX (25 mg. $\mathrm{kg}^{-1}$ ) group, (8) NPPN medium dose $\left(188 \mathrm{mg} \cdot \mathrm{kg}^{-1}\right)+\mathrm{CTX}\left(25 \mathrm{mg} \cdot \mathrm{kg}^{-1}\right)$ group, (9) NPPN high dose $\left(375 \mathrm{mg} \cdot \mathrm{kg}^{-1}\right)+$ CTX $\left(25 \mathrm{mg} \cdot \mathrm{kg}^{-1}\right)$ group, (1), (2), (3) group were orally administered $0.2 \mathrm{~mL}$ of normal saline; $(4) \sim(9)$ group were orally administered NPPN; continuous oral administration for 19 days.

\section{Inoculation of $\mathrm{H} 22$ hepatoma cells and intraperitoneal injection of CTX}

On the morning of the 6th day of administration, mice were given $\mathrm{H} 22$ hepatoma cells (National Infrastructure of Cell Line Resource, Beijing, China) for 7 days in the abdominal cavity of mice, and the mouse abdominal cavity was swabbed with $75 \%$ ethanol, and the sodium chloride injection in the syringe was pushed to mouse abdominal cavity, then take the mouse ascites, repeat several operations, get H22 liver cancer cell suspension, take $10 \mu \mathrm{L}$ of cell suspension in a clean EP tube, add $1990 \mu \mathrm{L}$ saline, mix and count. The concentration of the saline cells was adjusted to $2.5 \times 10^{7}$ cells $/ \mathrm{mL}$, and the mice in the $(2) \sim(9)$ group were inoculated with $0.2 \mathrm{~mL}$ of tumor cell suspension. After inoculation, mice in groups (3), (7), (8) and (9) were intraperitoneally injected with cyclophosphamide drug solution for 14 consecutive days.

\section{Determination of tumor inhibition rate in the $\mathrm{H} 22$ tumor- bearing mice}

On the 14th day after inoculation, after the last administration, the mice fasted for $12 \mathrm{~h}$, and the mice were sacrificed by cervical dislocation. The tumor tissues were removed and weighed. The tumor inhibition rate $(\%)=(1$ - treatment group mean tumor weight / saline group mean tumor weight) $\times 100 \%$.

\section{Statistical methods}

The LSD analysis of variance (ANOVA) was used for the significance test. Data were all presented as EMBED Eq. $3 \bar{x} \pm s$; one-way ANOVA and comparison among groups were performed using the SPSS 17.0 statistical software and a probability of less than $0.05(p<0.05)$ was considered statistically significant. 


\section{Results}

\section{Extraction of NPPN from CPPN}

In our previous report, we were able to isolate CPPN from the herb residue of Panax notoginseng with the content of polysaccharides is $56.2 \%$ and the application of CPPN prolonged the lifespan of $\mathrm{H} 22$ tumor-bearing mice by boosting the immune system [13]. To further validate that the polysaccharide portion of the CPPN played a major role in the boosting of the immune system, CPPN was further purified by an anion-exchange chromatography column of DEAE Sepharose Fast Flow to enrich the polysaccharide portion. The NPPN was eluted with water and four APPN fractions (APPN I, APPN II, APPN III, APPN IV) were eluted with and $0.1,0.2,0.3,0.4 \mathrm{~mol} \cdot \mathrm{L}^{-1}$ sodium chloride solutions respectively (Fig. 1). After the dialysis and freeze-dried, the yields of the NPPN, APPN I, APPN II, APPN III, and APPN IV were 30.51, 29.56, 14.72, 7.43, $2.54 \%$ respectively. The $\mathrm{Mw}, \mathrm{Mn}$ and dispersity of each fraction and the contents of polysaccharides were measured. The results are shown in Table 1 . The contents of polysaccharides of NPPN was the highest, which increased to $88.4 \%$ from $56 \%$ of CPPN (Table 1). The HPGPC analysis revealed that NPPN was the purest extraction from Panax notoginseng with a single peak (Fig. 1c) compared to other extractions (Fig. 1b, d, e, f, and g). Thus, NPPN was selected in the future experiment combined with CTX treatment.
Table 1 The molecular weights and the contents of polysaccharides from Panax notoginseng

\begin{tabular}{lllll}
\hline Sample & $\mathbf{M n}$ & $\mathbf{M w}$ & $\mathbf{D}(\mathbf{M w} / \mathbf{M n})$ & Content (\%) \\
\hline CPPN & 9207 & 97,660 & 10.61 & 56.2 \\
NPPN & 6906 & 18,100 & 2.62 & 88.4 \\
APPN I & 7708 & 70,470 & 9.142 & 76.1 \\
APPN II & 15,190 & 105,600 & 6.953 & 48.3 \\
APPN III & 9431 & 92,330 & 9.79 & 36.2 \\
APPN IV & 10,060 & 90,170 & 8.967 & 32.4 \\
\hline
\end{tabular}

\section{Administration of NPPN with CTX ameliorated the immunosuppression caused by CTX}

CTX is a well-known immunosuppressant and chemotherapy drug for cancer treatment, which also causes severe immunosuppression and myelosuppression. Using the organ indexes of the spleen, and thymus, the two major immune organs of a mouse, we evaluate the overall impaction of NPPN on the immune status in CTX treated mice, compared to the normal group, both spleen and thymus indexes of the CTX-treated group were reduced significantly $(P<0.01)$, which indicated the immunosuppression resulted from CTX treatment (Table 2). Compared to the CTX-treated group, the high-dose NPPN plus cyclophosphamide group increase thymus indexes $(P<0.05)$.

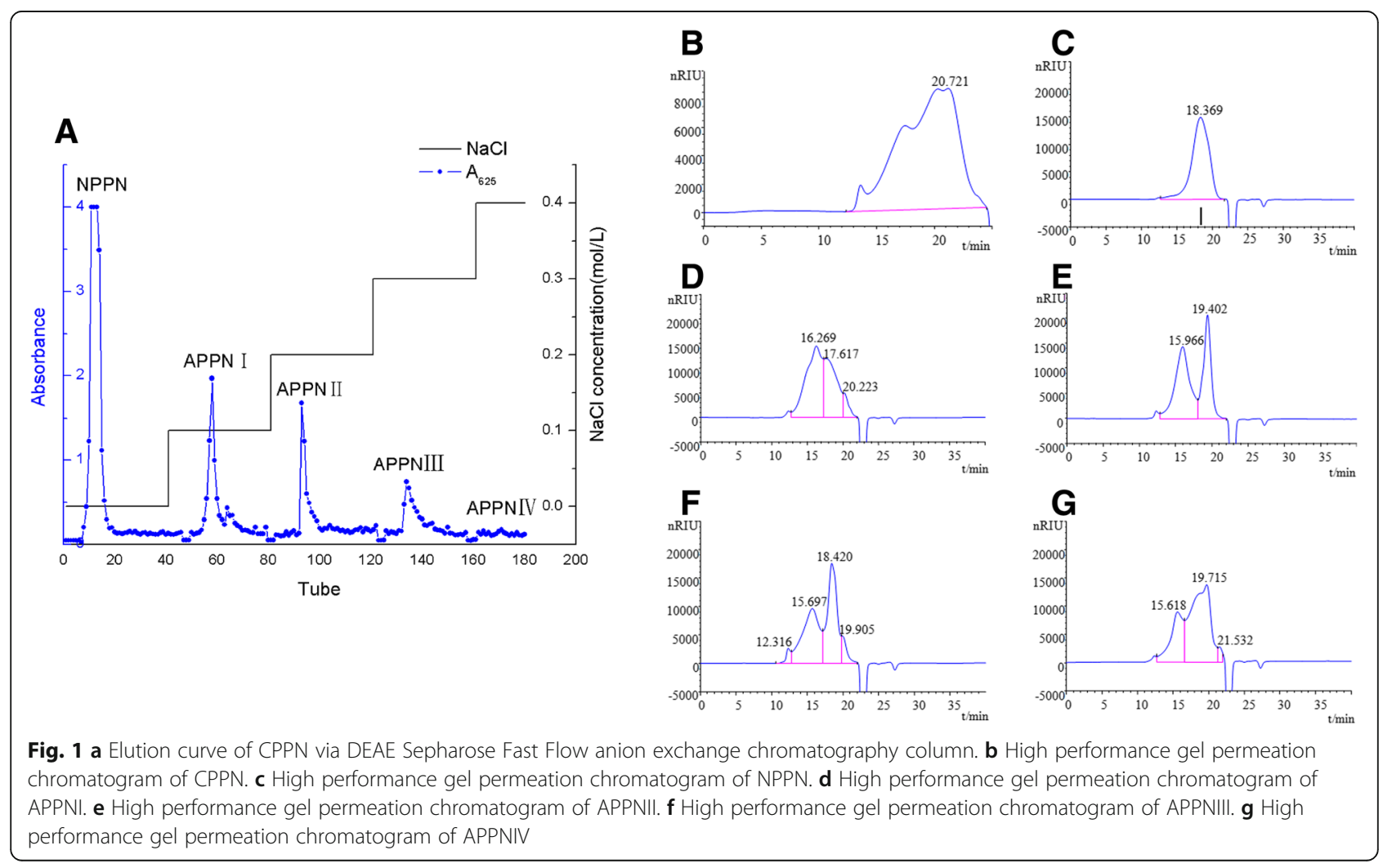


Table 2 Effect of NPPN on immune function in mice with immunosuppression caused by CTX $(\bar{x} \pm s, n=10)$

\begin{tabular}{|c|c|c|c|c|c|c|c|c|}
\hline Group & $\begin{array}{l}\text { Dosage } \\
\left(\mathrm{mg} \cdot \mathrm{kg}^{-1}\right)\end{array}$ & $\begin{array}{l}\text { Thymus } \\
\text { index }\end{array}$ & $\begin{array}{l}\text { Spleen } \\
\text { index }\end{array}$ & $\begin{array}{l}\text { Stimulation } \\
\text { index }\end{array}$ & $\begin{array}{l}\text { Absorbance value of serum } \\
\text { hemolysin }\end{array}$ & $\begin{array}{l}\text { NK cell } \\
\text { activity (\%) }\end{array}$ & K & $a$ \\
\hline Normal & - & $3.80 \pm 0.80^{* *}$ & $3.05 \pm 0.68^{* *}$ & $1.07 \pm 0.05^{* *}$ & $0.59 \pm 0.01^{* *}$ & $62.16 \pm 4.59^{* *}$ & $0.023 \pm 0.007^{*}$ & $5.12 \pm 0.37^{* *}$ \\
\hline CTX & 80 & $0.68 \pm 0.08$ & $1.17 \pm 0.13$ & $0.91 \pm 0.05$ & $0.36 \pm 0.04$ & $25.42 \pm 8.33$ & $0.017 \pm 0.004$ & $4.69 \pm 0.25$ \\
\hline $\begin{array}{l}\text { NPPN-L + } \\
\text { CTX }\end{array}$ & $93+80$ & $0.76 \pm 0.09$ & $1.33 \pm 0.29$ & $0.96 \pm 0.04^{* *}$ & $0.55 \pm 0.05^{* *}$ & $35.56 \pm 6.47^{* *}$ & $0.024 \pm 0.006^{*}$ & $4.94 \pm 0.47$ \\
\hline $\begin{array}{l}\text { NPPN-M+ } \\
\text { CTX }\end{array}$ & $188+80$ & $0.86 \pm 0.12$ & $1.22 \pm 0.27$ & $0.97 \pm 0.05^{* *}$ & $0.57 \pm 0.03^{* *}$ & $29.07 \pm 5.27$ & $0.022 \pm 0.004$ & $4.77 \pm 0.40$ \\
\hline $\begin{array}{l}\text { NPPN-H+ } \\
\text { CTX }\end{array}$ & $375+80$ & $0.98 \pm 0.06^{*}$ & $1.29 \pm 0.17$ & $0.94 \pm 0.01$ & $0.57 \pm 0.03^{* *}$ & $35.13 \pm 5.93^{* *}$ & $0.025 \pm 0.005^{* *}$ & $5.10 \pm 0.28^{* *}$ \\
\hline
\end{tabular}

Notes: ${ }^{*} P<0.05,{ }^{* *} P<0.01$ vs. CTX

We further evaluated the effect of NPPN application on cellular and humoral immunity as the indicators of the strength of the immune system including the proliferation of $\mathrm{T}$ lymphocytes and the measurement of the serum hemolysin. When $\mathrm{T}$ lymphocytes are stimulated by Concanavalin, a proliferative response occurs in the mother cells. Mitochondrial hydrolase in living cells, especially in proliferating cells, can decompose MTT into blue-purple crystals, and its optical density value can reflect the proliferation of $\mathrm{T}$ lymphocytes. The result of the measurement of the proliferation of $\mathrm{T}$ lymphocytes was shown in Table 2 and Fig. 2a. Compared with the normal group, the proliferation of $\mathrm{T}$ lymphocytes in the CTX group was significantly decreased than that in the normal group $(P<0.01)$, indicating that the activity of the proliferation of $\mathrm{T}$ lymphocytes was suppressed. When NPPN was applied together with CTX, though the highest dosage of NPPN was combined with CTX increased the proliferation of $\mathrm{T}$ lymphocytes of mice without significance, both lowest and medium dosages significantly increase the proliferation of $\mathrm{T}$ lymphocytes compared to the CTX-treated group $(P<0.01)$ (Fig. 2a).

The mechanism of measuring the serum hemolysin content of mice is that sheep red blood cells enter the body and stimulate the body to produce specific antibody hemolysin, which is an anti-sheep red blood cell antibody. The antigen-antibody binds in vitro to form an antigen-antibody complex, exposing the $\mathrm{C} 1 \mathrm{q}$ binding points of complement, activating complement, and causing sheep red blood cells to lyse. By examining the amount of antibodies produced by the body, the body's humoral immune function status is reflected. The result of the measurement of the serum hemolysin was shown in Table 2 and Fig. 2b. Compared with the normal group, the serum hemolysin antibody content in the CTX group was significantly decreased $(P<0.01)$, indicating that the production of serum hemolysin antibodies was suppressed. When NPPN was applied together with CTX, all serum hemolysin contents of the low, medium and high dose groups were significantly higher than that of the CTX group $(P<0.01)$. In addition, all serum hemolysin contents of the low, medium and high dose groups had increased to the same level as the normal group, which indicated a full recovery of the activity of antibody hemolysin antibody under the NPPN and CTX combined treatment.

We further evaluated the effect of NPPN application on specific cell activities as the indicators of the strength of the immune system including NK cell activity and phagocytic capability of macrophage. As shown in Table 2 and Fig. 2c, compared with the normal group, the application of CTX strongly deceased the NK cell activity $(P<0.01)$, which indicated the immunosuppression of the CTX treated mice. When NPPN was applied to mice with CTX at different dosages, the NK cell activity of the low and high dose groups was significantly higher than that of the CTX group $(P<0.01)$. The result suggests NPPN increased the NK cell activity.

Phagocytosis of macrophages is also a crucial indicator of immune function. We perform the carbon clearance test to evaluate the phagocytic capability of macrophages. The results of the carbon clearance test are shown in Table 2 and Fig. 3d. The phagocytic index $\alpha$ of the CTX group were significantly lower than those of the control group $(P<0.05)$, indicating the immunosuppression established by CTX. Though the lowest and middle dosage of NPPN was combined with CTX increased, the high dosages significantly increase the phagocytic indexes compared to the CTX-treated group $(P<0.01)$ (Fig. 2d). This result indicates the combination of NPPN with CTX improved the macrophage activity suppressed by CTX.

\section{NPPN combined with CTX improved myelosuppression caused by CTX treatment}

After the evaluation of NPPN improved the immunosuppression caused by CTX, we investigated the effect of NPPN on the amelioration of myelosuppression caused by CTX, when NPPN was applied together with CTX using blood cell analysis. Four blood cell count rests 


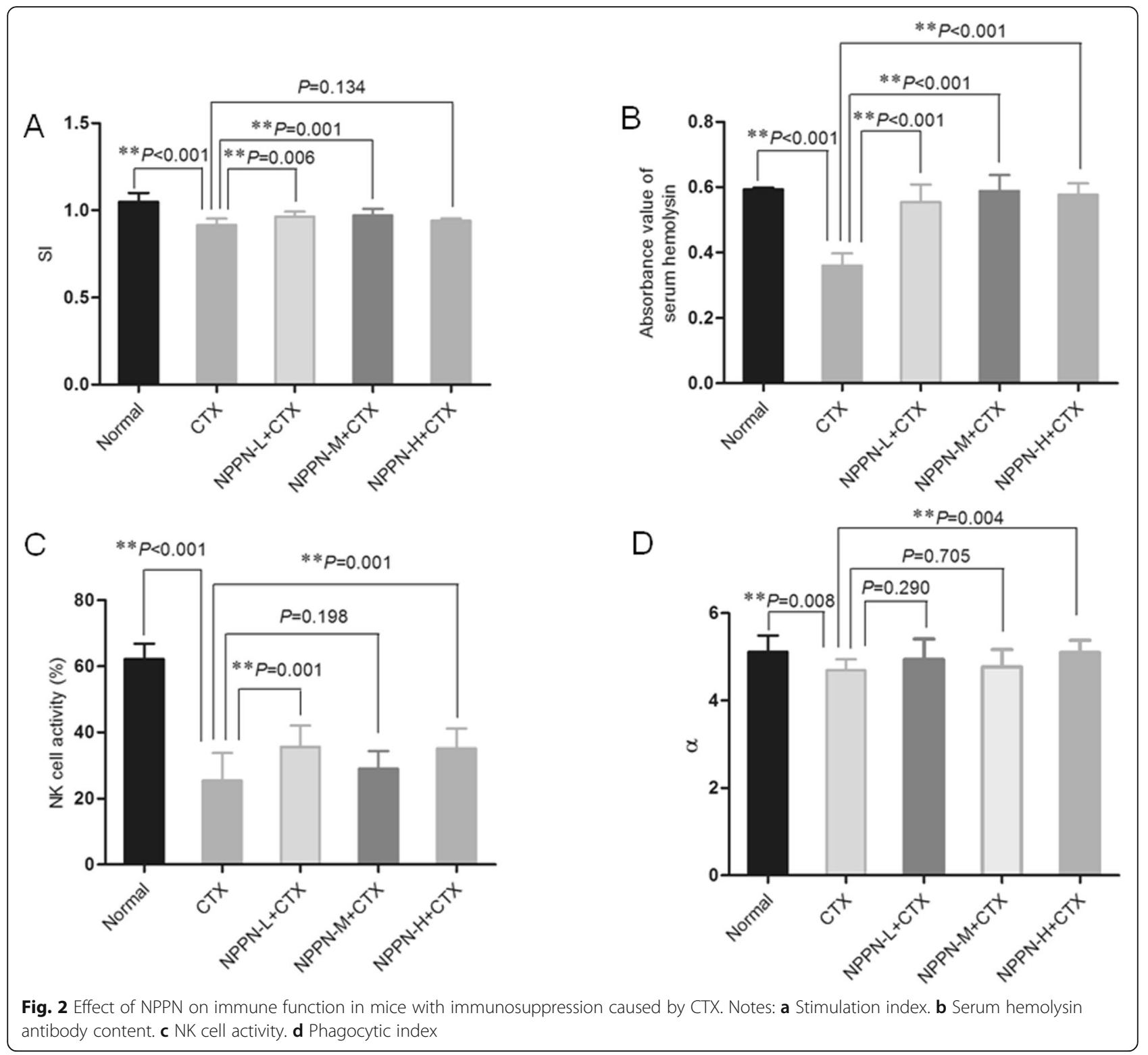

were determined by an automatic blood cell analyzer. The results of blood count tests are shown in Table 3. 4 blood cell count results in the CTX group were significantly lower than those in the normal group $(P<0.05$ or $P<0.01)$ including white blood cells, lymphocyte numbers, red blood cell and platelet.

This result indicates that the CTX treatment resulted in myelosuppression status in mice (Table 3 and Fig. 3). When NPPN was applied together with CTX, four blood cell count indicators showed significant increases up to the levels of the CTX group including the white blood cell, lymphocyte numbers, red blood cell, platelet $(P<$ 0.01 or $P<0.05$ ). The white blood cell (Fig. 3a) and lymphocyte numbers (Fig. 3b) in the medium and high dose groups of NPPN were higher than that of the CTX group $(P<0.01$ or $P<0.05)$; the red blood cell (Fig. 3c) in the high dose groups of NPPN were higher than that of the CTX group $(P<0.05)$; the platelet counts (Fig. $3 \mathrm{~d})$ of the low and high dose groups of NPPN were significantly higher than those of the CTX group $(P<0.05)$.

\section{NPPN combined with CTX enhanced tumor inhibition effect of CTX on $\mathrm{H} 22$ tumor-bearing mice}

The previous results indicated NPPN combined with CTX as an immunostimulator ameliorated the immunosuppression and myelosuppression resulted from the administration of CTX alone. We investigated the antitumor activity of the combination treatment with NPPN and CTX on H22 liver tumor-bearing mice. The results are shown in Table 4 and Fig. 4. When 


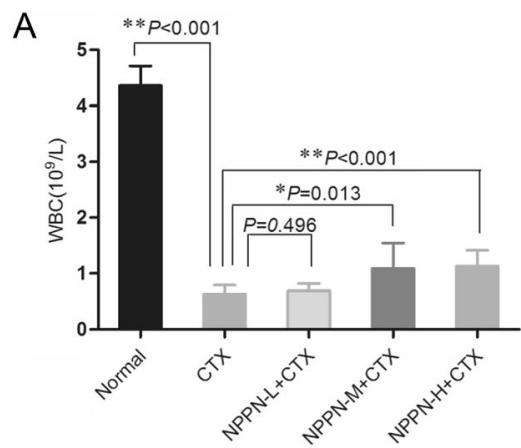

C

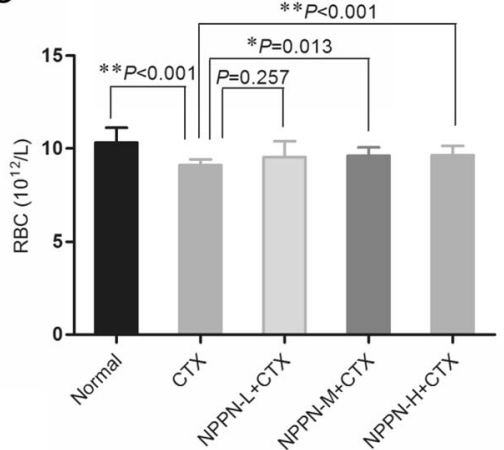

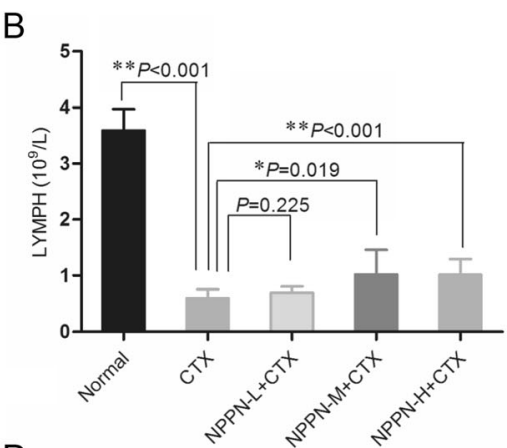

$\mathrm{D}$

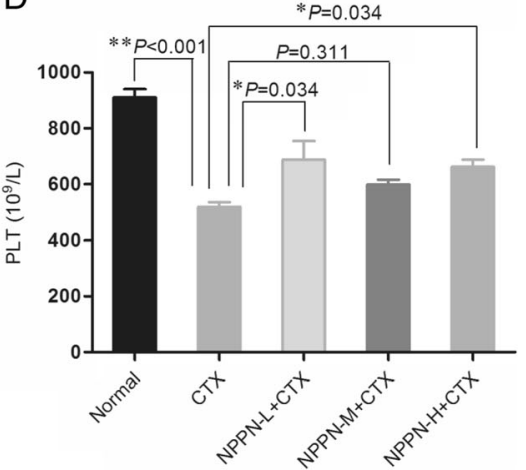

Fig. 3 Effect of NPPN on hematological parameters in mice with myelosuppression caused by CTX. Notes: a WBC. b LYMPH. c RBC. $\mathbf{d}$ PLT

CTX was applied to the H22 tumor-bearing mice alone, the tumor inhibition rate reached $67.99 \%$ compared with the normal group treated with saline. The application of NPPN alone showed 47.87, 63.12 and $63.23 \%$ tumor inhibition rates at the low, medium and high NPPN dosage compared with the normal group treated with saline, which is consistent with our previous report that CPPN with only 56\% of polysaccharide contents prolonged the lifespan of the H22 tumor-bearing mice. This result indicates the polysaccharide portion of CPPN plays a major role in its antitumor activity against HCC [14]. When NPPN combined with CTX, both medium dosage and high dosage of NPPN combined with CTX groups showed significant increases in tumor inhibition rates compared with the CTX group alone $(P<0.05)$.

\section{Discussions}

Our previous studies demonstrated that CPPN administration could effectively prolong the lifespan of tumorbearing mice via boosting the host immune system as well as weak cytotoxicity against HCC. CPPN may have a potential application for the treatment of hepatocellular carcinoma [14]. In order to explore the pharmacodynamics substance basis of Panax notoginseng polysaccharide, the CPPN was further purified into NPPN and APPN. The effects of NPPN and three APPN on the proliferation of seven tumor cells in vitro were investigated in the previous experiments. The seven tumor cells were: H22 mouse hepatoma cells, S180 mouse ascites tumor cells, YAC-1 lymphocytes. Tumor cells, MCF-7 human breast cancer cells, 4 T1 mouse breast cancer cells, B16 mouse melanoma cells and

Table 3 Effect of NPPN on hematological parameters in mice with immunosuppression $(\bar{x} \pm s, n=10)$

\begin{tabular}{|c|c|c|c|c|c|}
\hline Group & Dosage $\left(\mathrm{mg} \cdot \mathrm{kg}^{-1}\right)$ & WBC $\left(10^{9} / L\right)$ & $\operatorname{LYMPH}\left(10^{9} / \mathrm{L}\right)$ & $\operatorname{RBC}\left(10^{12} / \mathrm{L}\right)$ & $\operatorname{PLT}\left(10^{9} / \mathrm{L}\right)$ \\
\hline Normal & - & $4.35 \pm 0.81^{* *}$ & $3.57 \pm 0.39^{* *}$ & $10.32 \pm 0.80^{* *}$ & $812.2 \pm 89.1^{* *}$ \\
\hline CTX & 80 & $0.62 \pm 0.12$ & $0.60 \pm 0.17$ & $9.11 \pm 0.34$ & $520.70 \pm 52.17$ \\
\hline NPPN-L + CTX & $93+80$ & $0.69 \pm 0.12$ & $0.71 \pm 0.25$ & $9.53 \pm 0.87$ & $687.50 \pm 211.04^{*}$ \\
\hline NPPN-M + CTX & $188+80$ & $1.08 \pm 0.35^{*}$ & $1.02 \pm 0.44^{* *}$ & $9.62 \pm 0.44$ & $598.70 \pm 55.26$ \\
\hline NPPN-H + CTX & $375+80$ & $1.10 \pm 0.31^{* *}$ & $1.02 \pm 0.28^{* *}$ & $9.67 \pm 0.47^{*}$ & $661.80 \pm 83.47^{*}$ \\
\hline
\end{tabular}

Notes: ${ }^{*} P<0.05, * * P<0.01$ vs. CTX 
Table 4 Effects of NPPN combined with CTX on inhibition rate in H22 tumor-bearing mice (EMBED Eq. $3 \bar{x} \pm s, n=5$ )

\begin{tabular}{llll}
\hline Group & Dosage $\left(\mathbf{m g} \cdot \mathbf{k g}^{-\mathbf{1}}\right)$ & Tumor weight & Anti-tumor rate (\%) \\
\hline Normal & - & - & - \\
NS & - & $1.36 \pm 0.10^{* *}$ & - \\
CTX & 25 & $0.44 \pm 0.12^{\# \#}$ & 67.99 \\
NPPN-L & 93 & $0.71 \pm 0.25^{\# \# ~ *}$ & 47.87 \\
NPPN-L + CTX & $93+25$ & $0.32 \pm 0.04 \# \#$ & 76.53 \\
NPPN-M & 188 & $0.50 \pm 0.20^{\# \#}$ & 63.12 \\
NPPN-M + CTX & $188+25$ & $0.25 \pm 0.05 \# \#$ *\# & 81.37 \\
NPPN-H & 375 & $0.50 \pm 0.17^{\# \#}$ & 63.23 \\
NPPN-H + CTX & $375+25$ & $0.20 \pm 0.05^{\# \# *}$ & 85.17
\end{tabular}

Notes: ${ }^{\#} P<0.05,{ }^{\# \#} P<0.01$ vs. NS; ${ }^{*} P<0.05,{ }^{*} P<0.01$ vs. CTX

CT26.WT mouse colon cancer cells, it was found that only NPPN inhibited the growth of each cell line. The pre-experiment also examined the effects of NPPN and three kinds of APPN on the proliferation of human periodontal ligament stem cells and mouse osteoblasts in vitro, the results showed that NPPN and APPN I on human periodontal Membrane stem cells have the effect of promoting proliferation. NPPN, APPN I, APPN II and
APPN III can promote the proliferation of mouse osteoblasts. Therefore, this experiment used NPPN as experimental samples.

In this study, a CTX-induced immunosuppression combined with a myelosuppressive mouse model was established by intraperitoneal injection of CTX at a dose of $80 \mathrm{mg} / \mathrm{kg} / \mathrm{d}$ for 5 days. The NPPN was continuously administered to the stomach for 10 days, and the mice

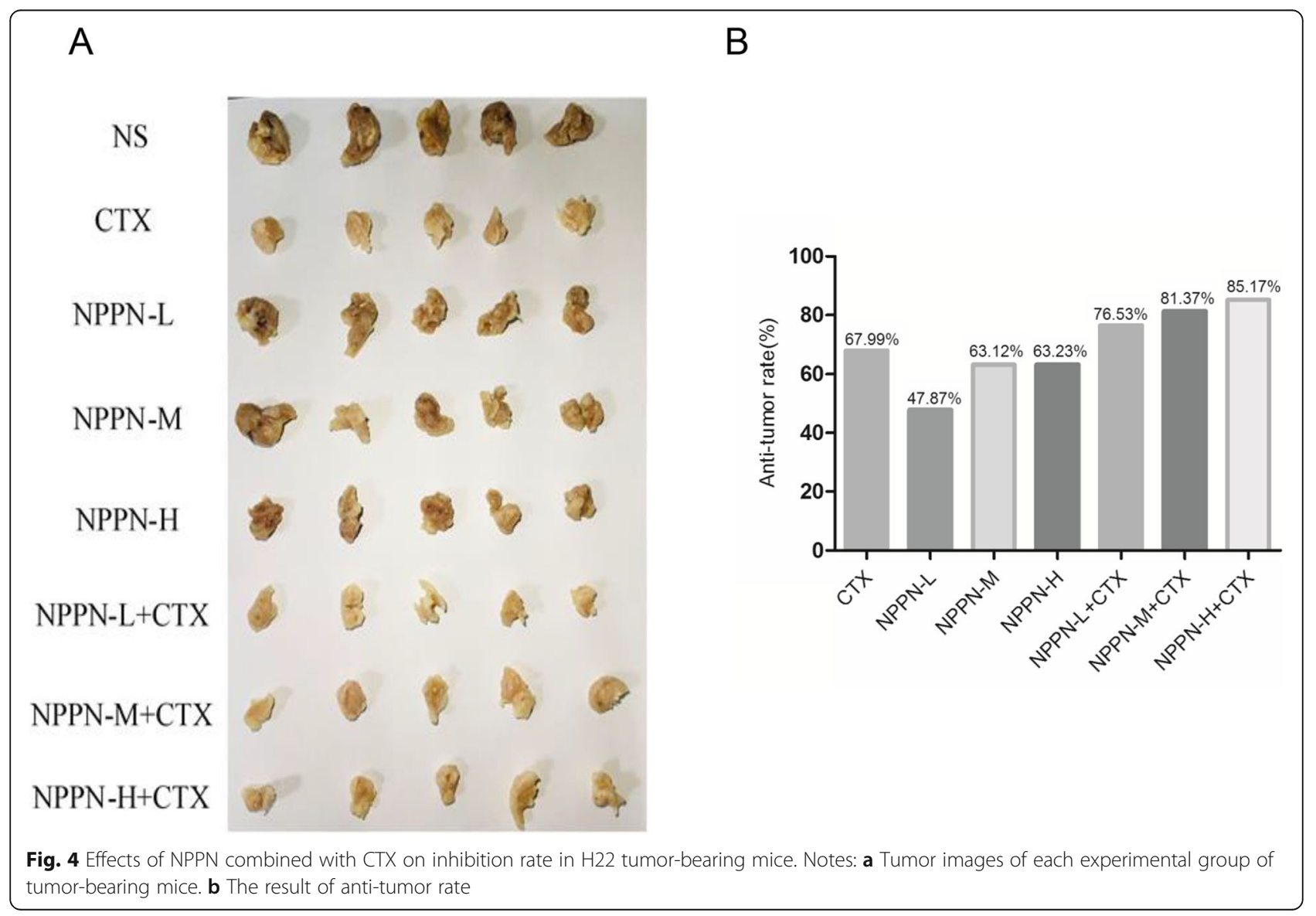


were sacrificed. The peripheral blood was measured by an automatic blood cell analyzer. Four blood cell count results were determined by blood cell analyzer and the 4 blood cell count results were higher than that of the CTX group $(P<0.01$ or $P<0.05)$. The phagocytosis ability and serum hemolysin level determined by peripheral blood were not different between the NPPN group and the normal group. The NK cell activity and lymphocyte proliferative response measured by spleen were significantly lower in the NPPN group than in the normal group $(P<0.01)$, suggesting that the main target of the NPPN in CTX-induced immunosuppression combined with myelosuppressive mouse model is in the blood system. Cancer chemotherapy drugs are aimed at actively growing cells. In addition to malignant tumor cells, cells in bone marrow hematopoietic stem cells, digestive tract mucosa, skin and its appendages, endometrium, and ovary are also rapidly renewed. This is the histological basis for the corresponding adverse effects of chemotherapy drugs. It can be considered that almost all chemotherapeutic drugs have myelosuppressive effects, the difference is only in degree. CTX is an alkylating agent antitumor drug and a cytotoxic immunosuppressive drug. It is a broadspectrum anti-tumor drug, effective for leukemia and solid tumors, and one of the most potent and widely used drugs among various immunosuppressants currently in use. Due to its good clinical efficacy, the application range is increasingly wide. CTX enters the body and is hydrolyzed by excess phosphoramidase or phosphatase present in the liver or tumor to act as activated phosphoramide mustard. It cross-links with DNA, inhibits DNA synthesis, and interferes with RNA function. It is a cell cycle non-specific drug. Compared with other cytotoxic drugs, immunosuppressive effects are strong and long-lasting. CTX has a greater toxic side effect and myelosuppression is the most common toxicity. In conclusion, the NPPN has a repairing effect on hematopoietic function and immunosuppression induced by cyclophosphamide in mice, and it is speculated that the target is bone marrow hematopoietic stem cells, which has a repairing effect on DNA damage of bone marrow hematopoietic stem cells.

Based on NPPN, it can repair the hematopoietic function and immunosuppression to a certain degree induced by CTX in mice. We treated NPPN with CTX in H22 tumor-bearing mice, and found that the tumor weight was significantly lower in the NPPN medium and high-dose + CTX group compared with the CTX group $(P<0.05)$. Therefore, the combination of chemotherapeutic drugs and, NPPN which are cytotoxic to various tumor cells and has a repairing effect on hematopoietic function and immunosuppression caused by chemotherapy after bone marrow suppression in mice, will provide new possibilities for the treatment of tumors.

Nitrogen mustards (NMs) form cyclic aminium ions (aziridinium rings) by intramolecular displacement of the chloride by the amine nitrogen. This aziridinium group then alkylates DNA once it is attacked by the N-7 nucleophilic center on the guanine base. A second attack after the displacement of the second chlorine forms the second alkylation step that results in the formation of interstrand cross-links (ICLs) as it was shown in the early 1960s. At that time it was proposed that the ICLs were formed between N-7 atom of guanine residue in a $5^{\prime}-\mathrm{d}$ (GC) sequence [19]. Later it was clearly demonstrated that NMs form a 1, 3 ICL in the $5^{\prime}-\mathrm{d}$ (GNC) sequence [20-23].

The strong cytotoxic effect caused by the formation of ICLs is what makes NMs an effective chemotherapeutic agent. Other compounds used in cancer chemotherapy that have the ability to form ICLs are cisplatin, mitomycin C, carmustine, and psoralen [24]. These kinds of lesions are effective at forcing the cell to undergo apoptosis via $\mathrm{p} 53$, a protein that scans the genome for defects. Note that the alkylating damage itself is not cytotoxic and does not directly cause cell death [25].

NPPN has a protective effect on immune organs such as bone marrow, spleen and thymus in immunosuppressed mice induced by cyclophosphamide. The serum hemolysin level and macrophage phagocytosis index measured from peripheral blood showed no statistically significant difference between the high-dose NPPN group and the normal group, while the NK cell activity and T-lymphocyte proliferation index measured from the spleen showed a significant difference compared with the normal group. It suggests that NPPN has a stronger protective effect on peripheral blood than the spleen, and peripheral blood comes from bone marrow, suggesting that NPPN has a protective effect on bone marrow. Immunosuppressive cyclophosphamide targets are proliferative cells, while bone marrow stem cells are proliferative cells. The protective effect of NPPN on bone marrow stem cells and bone marrow is underway in our research group.

\section{Conclusion}

CPPN was separated and purified by DEAE Sepharose Fast Flow anion exchange column. The eluted part of $\mathrm{H}_{2} \mathrm{O}$ was dialyzed and freeze-dried to obtain NPPN. The content of polysaccharide in the NPPN was determined by the anthrone-sulfuric acid method to be $88.4 \%$, and the yield was $28.9 \%$. The weight-average molecular weight of the NPPN measured by high-performance gel chromatography was $18,100 \mathrm{Da}$, and the $\mathrm{pH}$ value of the NPPN solution was 7.35. 
NPPN can increase the thymus index, cellular immunity, humoral immunity, and bone marrow hematopoietic function of immunosuppressive and bone marrowsuppressed mice induced by the chemotherapy drug CTX.

NPPN were used to treat $\mathrm{H} 22$ tumor-bearing mice. Compared with the saline group, NPPN low, medium and high dose groups had higher tumor inhibition rates and significant differences $(P<0.01)$, the tumor inhibition rate of the medium and high dose group of NPPN was not different from that of the cyclophosphamide group. Compared with the cyclophosphamide group, the tumor inhibition rate of the medium and high doses of NPPN and cyclophosphamide combined increased the tumor inhibition rate and had significant differences $(P<0.05)$.

\begin{abstract}
Abbreviations
CPPN: Crude polysaccharide from Panax notoginseng; NPPN: Neutral polysaccharide from Panax notoginseng; APPN: Acid polysaccharide from Panax notoginseng; CTX: Cyclophosphamide; HCC: Hepatocellular carcinoma; Mw: Average molecular weight; Mn: Number average molecular weight; HPGPC: High performance gel permeation chromatography; MTT: 3-(4, 5dimethyl-2-thiazolyl)-2, 5-diphenyl-2-H-tetrazolium bromide; OD: Optical density; SI: Stimulation index; SRBC: Sheep red blood cells; LDH: Lactate dehydrogenase; WBC: White blood cell; LYMPH: Lymphocyte; RBC: Red blood cell; PLT: Platelet
\end{abstract}

\section{Acknowledgments}

Not applicable.

\section{Authors' contributions}

YHL completed the experiment of tumor inhibition rate of neutral panax notoginseng polysaccharide combined with cyclophosphamide on $\mathrm{H} 22$ bearing mice and wrote thesis; HYQ completed experiments to improve the immune organ index, cellular immunity, humoral immunity, and blood routine of cyclophosphamide-induced immune suppression and bone marrow suppression in mice with neutral panax notoginseng; YYZ completed the purification and physicochemical properties of neutral polysaccharides; TC has completed the experimental design and thesis revision; HW, LLC and ZYQ conduct the experiment operation instruction, HJW, XT, YLL, SL, HYL and $L Z$ took part in the experiment. The authors read and approved the final manuscript.

\section{Funding}

This study was supported by the National Natural Science Foundation of China (Project No. 81760698); 2019 Annual Science and Technology Department of Yunnan Province-Kunming Medical University Joint Research Project of Applied Basic Research (2019FE001(-030)); The seventh batch of Yunnan specialty plant polysaccharide engineering research center construction plan; Yunnan Provincial Department of Education Scientific Research Fund Project (No.2018JS708).

\section{Availability of data and materials}

All data generated or analysed during this study are included in this published article.

\section{Ethics approval and consent to participate}

The experimental protocol was established, according to the ethical guidelines of the Committee of Medical Ethics, National Health Department of China, and approved by the Ethics Committee of Kunming Medical University.

\section{Consent for publication}

Not Applicable.

\section{Competing interests}

The authors declare that they have no competing interests.

\section{Author details}

${ }^{1}$ School of Pharmaceutical Sciences and Yunnan Key Laboratory of Pharmacology for Natural Products, Kunming Medical University, Kunming 650500, China. ${ }^{2}$ Key Laboratory of Medicinal Chemistry for Natural Resource, Ministry of Education, Yunnan University, Kunming 650091, China.

${ }^{3}$ Department of Geriatrics, the First Affiliated Hospital of Kunming Medical University, Kunming 650032, China. ${ }^{4}$ Clinical skills center, Kunming Medical University, Kunming 650223, China. ${ }^{5}$ Basic Medical College of Kunming Medical University, Kunming 650500, China. 'Dali Nursing Vocational College, Dali 671006, China. ${ }^{7}$ Yunnan University of Traditional Chinese Medicine, Kunming 650200, China.

Received: 2 April 2020 Accepted: 16 December 2020

Published online: 07 January 2021

\section{References}

1. El Serag HB. Hepatocellular carcinoma. N Engl J Med. 2011;365(12):1118-27.

2. Shi JS, Jin $X$, Wang MQ, et al. Effect of resection following downstaging of unresectable hepatocelluar carcinoma by transcatheter arterial chemoembolization. C M J. 2012;125(2):197-202.

3. Chan AT, Leung SF, Ngan RK, et al. Overall survival after concurrent cisplatin-radiotherapy compared with radiotherapy alone in locoregionally advanced nasopharyngeal carcinoma. J Natl Cancer Inst. 2005;97(7):536-9.

4. Saba NF, Salama JK, Beitler JJ, et al. ACR appropriateness criteria ${ }^{\circledR}$ for nasopharyngeal carcinoma. Head Neck. 2016;38(7):979-86.

5. Wang MM, Tian HM, Li G, et al. Significant benefits of adding neoadjuvant chemotherapy before concurrent chemoradiotherapy for locoregionally advanced nasopharyngeal carcinoma: a meta-analysis of randomized controlled trials. Oncotarget. 2016;7(30):48375-90.

6. Chen XM, Nie WJ, Fan SR, et al. A polysaccharide from Sargassum fusiforme protects against immunosuppression in cyclophosphamide-treated mice. Carbohydr Polym. 2012;90(2):1114-9.

7. Baig H, Somlo B, Eisen M, et al. Appropriateness of granulocyte colonystimulating factor use in patients receiving chemotherapy by febrile neutropenia risk level. J Oncol Pharm Pract. 2019;25(7):1576-85.

8. Gao H, Wang FZ, Lien EJ, et al. Immunostimulating polysaccharides from Panax notoginseng. Pharm Res. 1996;13(8):1196-200.

9. Lien EJ. Fungal metabolites and Chinese herbal medicine as immunostimulants. Prog Drug Res. 1990;34:395-420.

10. Li XY. Immunomodulating Chinese herbal medicines. Mem Inst Oswaldo Cruz. 1991;86(Suppl 2):159-64.

11. Ohtani K, Mizutani K, Hatono S, et al. Sanchinan-A, a reticuloendothelial system activating arabinogalactan from sanchi-ginseng (roots of Panax notoginseng). Planta Med. 1987;53(2):166-9.

12. Zhao SY, Chen T, Zhang YW, et al. Extraction and determination of polysaccharide in Panax notoginseng. West China J Pharm Sci. 2011;26(05): 481-3.

13. Li HY, Gu LL, Zhong YY, et al. Administration of polysaccharide from Panax notoginseng prolonged the survival of $\mathrm{H} 22$ tumor-bearing mice. Oncotargets Ther. 2016;9:3433-41.

14. Llovet JM, Di Bisceglie AM, Bruix J, et al. Design and endpoints of clinical trials in hepatocellular carcinoma. J Natl Cancer. 2008;100(10):698-711.

15. Qu JY, Tian M, He JH, et al. Impact of polysaccharides of Hedyotis diffusa on immune function in immunosupperession mice. Chin Med Mat. 2015;38(09): 1942-5.

16. Ye YX, Lin L, Zhao JX, et al. Effect of polysaccharides of Eucommin ulmides leaves on immune function in immunosuppression mice. Chin Med Mat. 2015;38(07):1496-8.

17. Li ZH, Zhang N, Dong WR, et al. Effect of polysaccharides of Radix scrophulariae on immune function in mice under normal physiological and hypoimmunical state. J China Pharm. 2017;28(10):1316-9.

18. Li HY, Zhong YY, Li S, et al. Isolation and purification of Panax notoginseng polysaccharide and its effect on proliferation of human periodontal ligament stem cells and mice osteoblasts in vitro West China. J Pharm Sci. 2019;34(05):433-9.

19. Yoshikawa M, Murakami T, Ueno T, et al. Bioactive saponins and glycosides. VIII. ${ }^{(1)}$ Notoginseng (1): new dammarane-type triterpene oligoglycosides, 
notoginsenosides- $A,-B,-C$, and $-D$, from the dried root of Panax notoginseng (BURK.) F. H. CHEN. C Chem Pharm Bull. 1997;45(6):1039-45.

20. Li HZ. A novel hexa-nordammarane glycoside from the roots of Panax notoginseng. Chin Chem Lett. 2001;12:59-62.

21. Ma WG, Mizutani M, Malterud KE, et al. Saponins from the roots of Panax notoginseng. Phytochemistry. 1999;52(6):1133-9.

22. Sun $H X$, Yang ZG, Ye YP. Structure and biological activity of protopanaxatriol-type saponins from the roots of Panax notoginseng. Int Immunopharmacol. 2006;6(1):14-25,

23. Yoshikawa M, Morikawa T, Yashiro K, et al. Bioactive saponins and glycosides. XIX. ${ }^{(1)}$ Notoginseng (3): immunological adjuvant activity of notoginsenosides and related saponins: structures of notoginsenosides-L, $-\mathrm{M}$, and $-\mathrm{N}$ from the roots of Panax notoginseng (BURK.) F. H. CHEN. Chem Pharm Bull. 2001;49(11):1452-6.

24. Wan JB, Lai CM, Li SP, et al. Simultaneous determination of nine saponins from Panax notoginseng using HPLC and pressurized liquid extraction. J Pharm Biomed Anal. 2006;41(1):274-9.

25. Liu JW, Tian SJ, de Barry J, et al. Panaxadiol glycosides that induce neuronal differentiation in neurosphere stem cells. J Nat Prod. 2007;70(8):1329-34.

\section{Publisher's Note}

Springer Nature remains neutral with regard to jurisdictional claims in published maps and institutional affiliations.

Ready to submit your research? Choose BMC and benefit from:

- fast, convenient online submission

- thorough peer review by experienced researchers in your field

- rapid publication on acceptance

- support for research data, including large and complex data types

- gold Open Access which fosters wider collaboration and increased citations

- maximum visibility for your research: over $100 \mathrm{M}$ website views per year

At $\mathrm{BMC}$, research is always in progress.

Learn more biomedcentral.com/submissions 